\title{
Anti-Inflammatory Activity of the Essential Oil Citral in Experimental Infection with Staphylococcus aureus in a Model Air Pouch
}

\author{
Hellen Braga Martins, ${ }^{1}$ Nathan das Neves Selis, ${ }^{1}$ Clarissa Leal Silva e Souza, ${ }^{2}$ \\ Flávia S. Nascimento, ${ }^{2}$ Suzi Pacheco de Carvalho, ${ }^{1}$ Lorena D'Oliveira Gusmão, ${ }^{2}$ \\ Jannine dos Santos Nascimento, ${ }^{2}$ Anne Karoline Pereira Brito, ${ }^{2}$ Samira Itana de Souza, \\ Marcio Vasconcelos de Oliveira, ${ }^{2}$ Jorge Timenetsky, ${ }^{3}$ Regiane Yatsuda, ${ }^{2}$ \\ Ana Paula T. Uetanabaro, ${ }^{1}$ and Lucas M. Marques ${ }^{1,2}$ \\ ${ }^{1}$ State University of Santa Cruz (UESC), Campus Soane Nazaré de Andrade, Ilhéus, BA, Brazil \\ ${ }^{2}$ Multidisciplinary Institute of Health, Federal University of Bahia (UFBA), Vitória da Conquista, BA, Brazil \\ ${ }^{3}$ Department of Microbiology, Institute of Biomedical Science, University of São Paulo (USP), São Paulo, SP, Brazil
}

Correspondence should be addressed to Lucas M. Marques; Imirandamarques@gmail.com

Received 4 October 2016; Accepted 27 December 2016; Published 21 February 2017

Academic Editor: Alessandra Russo

Copyright (C) 2017 Hellen Braga Martins et al. This is an open access article distributed under the Creative Commons Attribution License, which permits unrestricted use, distribution, and reproduction in any medium, provided the original work is properly cited.

\begin{abstract}
This study proposes to implement an alternative and effective strategy for local treatment of disease provoked by $S$. aureus. For the analysis of possible anti-inflammatory activity of essential oil, after establishing an air pouch model, 48 male mice of Balb/c were treated, infected, and euthanized at 4 and $8 \mathrm{~h}$. Thus, the total and differential white blood cells were counted in the animal's blood, and cytokines IL-1 $\beta$, IL- 6 , and TNF- $\alpha$ were titrated using ELISA in the air pouch lavage. Moreover, TNF- $\alpha$, IL- $1 \beta$, and IL-6 gene expression was analyzed through an RT-qPCR array, and $S$. aureus was quantified using qPCR. Our results, $p<0.05$, showed that EOC reduced the quantity of microorganisms. The group of mice treated with essential oil citral showed a significant decrease in TNF- $\alpha$ levels in tests demonstrating anti-inflammatory activity. There is no data about the mutual influence of the air pouch model, essential oil citral, and S. aureus. Thus, considering the interaction of these variables and the anti-inflammatory activity of the essential oil citral, we demonstrated, by alternative local treatment, a new antimicrobial agent that is not an antibiotic.
\end{abstract}

\section{Introduction}

Staphylococcus aureus is among the most pathogenic species of the staphylococci group, being responsible for causing endemic and epidemic infections, and can be acquired in hospitals or in the community, resulting in a high rate of morbidity and mortality worldwide [1]. Being an opportunistic pathogen, 20 to $30 \%$ of $S$. aureus is found on the skin and airways of the humans, being isolated from the skin environment and skin microbiota, respiratory tract, and other places [2].

This species may cause a host of illnesses ranging from mild skin diseases to potentially lethal diseases, including respiratory infections, bacteremia, septic arthritis, endocarditis, osteomyelitis, diarrhea, deep abscesses, and toxic shock syndrome. It can also lead to the development of diseases that compromise immunity, thus predisposing both healthy and immunocompromised individuals to the emergence of infections [3].

To eliminate this pathogen therapeutic measures play a critical role, since the host defense against $S$. aureus relies mainly on innate immunological mechanisms of the immune system. Initially, administering a broad-spectrum of antibiotics is recommended. However, because of antibiotic resistance and the increasing prevalence of MRSA (methicillin-resistant Staphylococcus aureus), vancomycin has been increasingly used as an experimental measure $[4,5]$. 
A promising alternative treatment for infections that should be considered is essential oils (EO), so called because of their composition based on lipophilic substances [6]. Essential oils are volatile secondary metabolites, which act through the cell wall and cell membrane, which may affect bacterial structures because of their cytotoxic and therapeutic properties, and protection against oxidation processes and deterioration caused by microorganisms $[7,8]$.

The essential oil citral (EOC) is composed of major constituents of monoterpenes (isomeric mixture of geranial and neral) and myrcene being found in a wide variety of plants, such as the lemon balm (Melissa officinalis) in lemon grass or lemongrass (Cymbopogon citratus) and verbena (Verbena officinalis) [9].

This oil has antibacterial and antifungal activity, analgesic and antispasmodic effects on uterine and intestinal tissue, antiparasitic action, and activity on the central nervous system, as well as being an anxiolytic and sedative, and these therapeutic properties of the compounds are explained by the presence of monoterpenes and myrcene. In addition to being antibacterial, EOC acts against gram-positive and gram-negative bacteria, and prolonged exposure to its use has not encountered resistance, thus justifying its use $[10,11]$.

The high mortality rate related to staphylococcal infections [12], the increase in $S$. aureus isolates resistant to antibiotics [13], and frequent and prolonged exposure to antimicrobial agents hinder the treatment of infections [14]. Therefore, alternative strategies to prevent or treat infections caused by $S$. aureus, sometimes minimizing or supplementing use of antibiotics, are necessary. Given the above background, with the changes in the epidemiology of infections, increased prevalence of resistance and significantly higher rates of morbidity and mortality, it is necessary to develop new treatment strategies for infections triggered by $S$. aureus [15]. Thus, we aim to analyze the anti-inflammatory activity of essential oil citral in experimental inoculation of $S$. aureus in an air pouch model, to provide solutions in local infections, promoting alternative therapeutic approaches to antibiotics and linking to advances in biotechnology.

\section{Materials and Methods}

This study was performed after approval by the Ethics Committee on Animal Use (CEUA) of the Multidisciplinary Institute of Health Campus Teixeira (IMS/CAT) of the Federal University of Bahia, with protocol number 021/2014.

2.1. Microorganism. For inflammatory induction, the reference strain of Staphylococcus aureus ATCC ${ }^{\circledR} 33591^{\mathrm{TM}}$ was used. This microorganism is resistant to the antibiotic methicillin (MRSA), positive mecA, nuc positive and PVL negative (according to data from The Global Bioresource Center). Brain Heart Infusion (BHI) and mannitol salt agar (MSA) were used for activation, reactivation, and cultivation of the strain of $S$. aureus, stored in a freezer at $-70^{\circ} \mathrm{C}$ for subsequent inoculation in animals. For reactivation of virulence factors of the strain, concentrated inoculum of the plated bacteria was prepared with sterile saline, and an amount of $20 \mu \mathrm{L}$ was applied on the ear of male $\mathrm{BALB} / \mathrm{c}$ mice anesthetized intraperitoneally with $100 \mathrm{uL}$ containing ketamine hydrochloride $(40 \mathrm{mg} / \mathrm{Kg})$ and xylazine $(10 \mathrm{mg} / \mathrm{Kg})$. After $24 \mathrm{~h}$, it was euthanized by increasing anesthesia followed by exsanguination, and the node of the throat, the same ear side used for inoculation, was removed with the aid of sterile surgical instruments and transferred to a falcon tube containing $1 \mathrm{~mL}$ of medium $\mathrm{RPMI}{ }^{\circledR}$. At the sediment, the sample was poured in a Petri dish to which $1 \mathrm{~mL}$ of medium RPMI was added further to be macerated. From the supernatant, $30 \mu \mathrm{L}$ was transferred to a plate with MSA medium for bacterial growth and maintained in a bacteriological oven at $37^{\circ} \mathrm{C}$ for $24 \mathrm{~h}$.

2.2. Essential Oil Citral. In the experiments we used essential oil citral (EOC) provided commercially by Sigma ${ }^{\circledR}$, and the dosage $(40 \mathrm{mg} / \mathrm{Kg}$ ) used was recommended according to the literature review [16-18], in which less answer variations were presented. For the test run, the citral was diluted in Tween $1 \%$.

2.3. Animal. Forty-eight male BALB/c mice, free of specified pathogens (SPF), were used at 8 weeks of age and were weighing on average $30 \mathrm{~g}$. The animals were kept in an environment with controlled and uniform conditions, with temperature of $21 \pm 2^{\circ} \mathrm{C}$ and humidity of $50 \pm 2 \%$, and subjected to the same procedures within each group. For the challenge, groups of twelve animals were made, six animals euthanized at the time of $4 \mathrm{~h}$ and six at the time of $8 \mathrm{~h}$, as follows:

C: uninfected mice, but with the administration of Tween $1 \%$, euthanized after 4 and 8 hours

CT: uninfected mice, but with the administration of the essential oil citral, euthanized after 4 and 8 hours

S: mice infected with $S$. aureus and euthanized after 4 and 8 hours

S + CT: mice infected with $S$. aureus and treated with essential oil citral and euthanized at 4 and 8 hours

The mice of group $\mathrm{C}$ were anesthetized with a $100 \mathrm{~mL}$ solution containing ketamine hydrochloride $(40 \mathrm{mg} / \mathrm{Kg})$ and xylazine $(10 \mathrm{mg} / \mathrm{Kg})$ by intraperitoneal injection, for developing a sterile compartment called an air pouch; $3 \mathrm{~mL}$ of sterile air was injected into the back of the animal, followed by $100 \mu \mathrm{L}$ Tween $1 \%$ injected into the air pouch. The mice of group CT were inoculated intraperitoneally at first with $100 \mathrm{~mL}$ of essential oil citral and anesthetized and then for developing the air pouch $3 \mathrm{~mL}$ of sterile air was injected into the back of the animal. The mice of group $S$ were anesthetized for developing an air pouch, and $3 \mathrm{~mL}$ of sterile air was injected into the back of the animal. Next, the mice were challenged with an injection of $100 \mu \mathrm{L}$ of ATCC 33591 strain into the air pouch. The inoculum was carried out by direct suspension, drawing from 3 to 5 colonies from the plates with mannitol salt medium, using a bacteriological loop. After this step, following protocol of CLSI (Clinical \& Laboratory Standards Institute), one tube aliquot was removed and placed in quartz cuvettes for reading a spectrophotometer to obtain the inoculum, following these parameters: 0.135 Abs $\left(660 \mathrm{~nm}\right.$ ), equivalent to $1 \times 10^{8} \mathrm{CFU} / \mathrm{mL}$ (colony forming 
units $/ \mathrm{mL}$ ). The mice of $\mathrm{S}+\mathrm{CT}$ group were inoculated intraperitoneally on the first time with the essential oil citral. After 30 minutes, they were anesthetized for developing an air pouch, by injecting $3 \mathrm{~mL}$ of sterile air into the back of the animal. Later, they were challenged with an injection of $100 \mu \mathrm{L}$ of ATCC 33591 strain, with inoculum carried out as stated in the $\mathrm{S}$ group. The animals were euthanized by increasing the anesthetic and exsanguination after 4 or 8 hours, according to experimental guidelines. Later, the same were subjected to a surgical procedure to remove the blood and wash the air pouch and the skin around the air pouch.

2.4. Obtaining Blood and Washing Skin and Air Pouch. Immediately after euthanasia, blood samples from animals were collected in tubes with and without EDTA for the total and differential leukocyte count. After trichotomy, the air pouch lavage was obtained by injecting $3 \mathrm{~mL}$ of sterile saline solution, proceeding with massage for homogenization. The fluid obtained was stored for analysis of the cytokines.

2.5. Leukocyte Count (Total and Differential). To quantify the total leukocytes, $20 \mathrm{~mL}$ of blood (collected in EDTA) was mixed with $400 \mu \mathrm{L}$ of fluid diluter (TURK). After $20 \mathrm{~min}$., the sample was transferred to a Neubauer chamber and then the optical microscope to perform the leukocyte count in a $40 \mathrm{x}$ magnification. The rating differential was performed with a 100-leukocyte count, stained with Quick Kit Dye (Panotic) at a 100x magnification, distinguishing them according to their type (neutrophils, monocytes, and lymphocytes). Two methods were used for counting the longitudinal and zigzag pattern. The absolute values for each leukocyte were calculated based on the total leukocyte count and percentage values found in the differential count.

2.6. Quantification of $S$. aureus. The genomic DNA of the samples was extracted according to the protocol for an Invitrogen Purelink ${ }^{\mathrm{TM}}$ Genomic DNA Kit (Invitrogen, São Paulo, SP, Brazil). Real-time PCR was performed in duplicate, using the Applied Biosystems ${ }^{\mathrm{TM}}$ platform. The technique was carried out by using TaqMan probes, using an amplification based protocol with a final volume of $25 \mu \mathrm{L}$ of reaction: $12.5 \mu \mathrm{L}$ of Master Mix (Applied Biosystems), $1.12 \mu \mathrm{L}$ of primer LTnucF (AAATTACATAAAGAACCTGCGACA), $1.12 \mu \mathrm{L}$ of primer LTnucR (GAATGTCATTGGTTGACCTTTGTA) $(20 \mathrm{pmoL})$, which are single copy genes, $0.75 \mu \mathrm{L}$ of probe $(10 \mathrm{mM}), 7.0 \mu \mathrm{L}$ of water, and $2.5 \mu \mathrm{L}$ of DNA. The parameters for amplification are $95^{\circ} \mathrm{C}-10 \mathrm{~min}$, followed by 30 cycles ( $95^{\circ} \mathrm{C}, 15$ seconds; $59^{\circ} \mathrm{C}, 1 \mathrm{~min}$ ). Quantitation was performed using an absolute quantization technique, based on a predetermined standard curve ranging $10^{7}-10$ microorganisms $/ \mu \mathrm{L}$. A new curve was added to each reaction, and the following parameters were established: $r^{2} \geq 0.950$ and efficiency between 95 and 105\%.

2.7. Dosage of Cytokines. The dosage of TNF- $\alpha$, IL- $1 \beta$, and IL- 6 cytokines was determined in the washed air pouch by ELISA (enzyme-linked immunosorbent assay) capture, according to the kit manufacturer guidelines (eBioscience, San Diego, CA, USA), in 96-well polystyrene plates, which confer high absorption. The reading was performed using a microplate reader Vivid Vision instrument with a wavelength of $450 \mathrm{~nm}$.

2.8. Gene Expression. The gene expression of inflammatory markers was assessed by an RT-qPCR array methodology. The mRNA of the air pouch skin samples was extracted by using Trizol, following the protocol supplied by the manufacturer. The obtained cDNA was performed using SuperScript ${ }^{\circledR}$ III Reverse Transcriptase Kit. The test gene expression SYBR ${ }^{\circledR}$ PCR Master Mix (Applied Biosystems) was conducted in custom-plates with the target genes IL- $1 \beta$, IL-6, and TNF- $\alpha$, with endogenous genes glyceraldehyde 3phosphate dehydrogenase (GAPDH) and $\beta$-actin, and genes MGDC control (Mouse Genomic DNA Contamination), RTC (Reverse Transcription Control), and PPC (Positive PCR Control). Amplification was performed in thermocycler StepOnePlus ${ }^{\mathrm{TM}}$ Software v2.3, with the following parameters for all genes: $95^{\circ} \mathrm{C}$ for 10 minutes, followed by 40 cycles at $95^{\circ} \mathrm{C}$ for 15 seconds and $60^{\circ} \mathrm{C}$ for $1 \mathrm{~min}$.

2.9. Immunohistochemistry. After processing and inclusion of samples in paraffin, histological sections with a thickness of $4 \mathrm{~mm}$ were used to study the immunohistochemistry. The sections were deparaffinized through a series of "baths" in xylene and alcohol. With the aim of improving the responses, one treatment stage of the blades was performed with citrate buffer. Endogenous peroxidase was blocked using a solution composed of methanol and hydrogen peroxide (30\%). Antibodies were used specific for macrophages CD 68 (AbD Serotec), being a marker of inflammatory response in tissue. A biotinylated anti-mouse secondary antibody was used (ImmPRESS ${ }^{\mathrm{TM}}$ Universal Reagent, Vector Laboratories). Subsequently, we used the avidin-biotin complex. The color development occurred by adding the chromogen 3,3diaminobenzidine (DAB, 3,3-diaminobenzidine, Easypath ${ }^{\circledR}$ ) on the cuts by the reaction thereof with the avidin-biotinperoxidase complex. The counterstaining was conducted by Harris hematoxylin bath. Twelve microscopic fields were analyzed with $40 \mathrm{x}$ magnification for counting the labeled cells in the ImageJ program.

2.10. Statistical Analysis. For analysis of cell count data, cytokines, and gene expression, GraphPad Prism 6.0 was used. Nonparametric tests were used: Kruskal-Wallis (when evaluating more than two groups) and Mann-Whitney (when evaluating two groups). Statistical differences were considered significant at $p<0.05$ using a 95\% confidence interval.

\section{Results}

By means of qPCR it was possible to quantify DNA and consequently the microbial load of S and S + CT groups in the samples of the washed air pouch being represented by the same colony forming units $(\mathrm{CFU}) / \mu \mathrm{L}$. Thus, in Figure 1, one can observe high probes $\left(>10^{4}\right.$ and $\left.<10^{5} \mathrm{CFU} / \mu \mathrm{L}\right)$ of S. aureus; however, the average of the groups was greater in the group infected at $4 \mathrm{~h}$. Compared to the treated group, this could be 


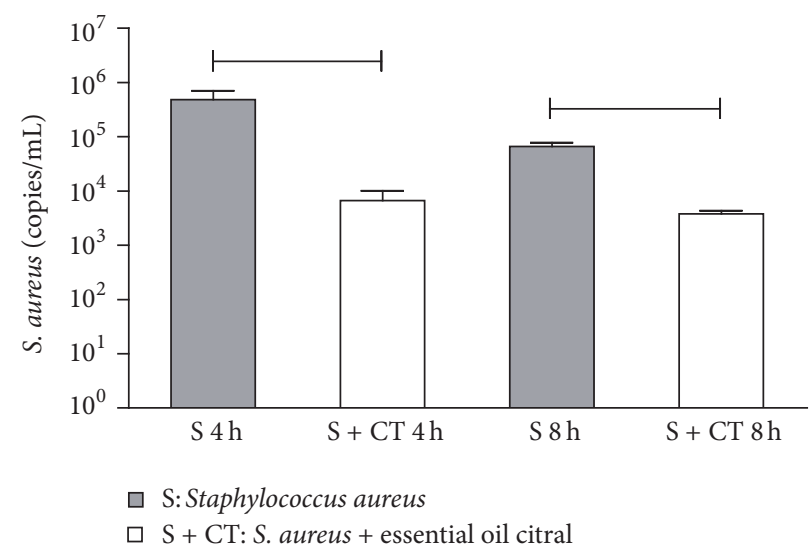

FIGURE 1: Quantification by qPCR of $S$. aureus $(\mathrm{CFU} / \mu \mathrm{L})$ in air pouch. Groups $(n=6)$ : $S$. aureus $(\mathrm{S})$ and $S$. aureus treated with citral $(\mathrm{S}+$ CT). ${ }^{\vdash}$ Significant difference using $p<0.05$, Mann-Whitney test.

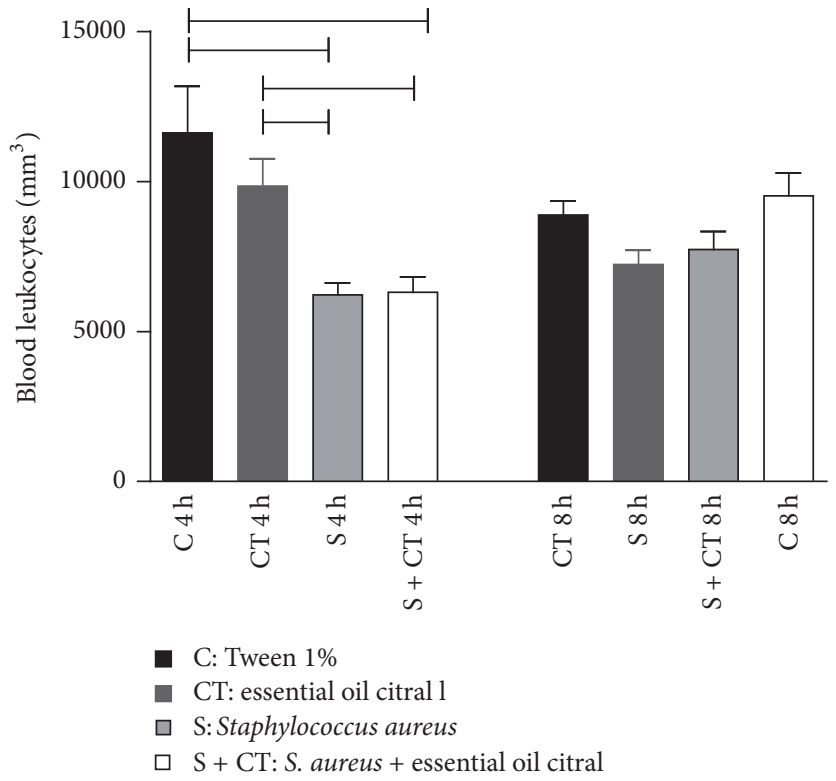

FIGURE 2: Quantification of total leukocytes in the blood of Balb/c after 4- and 8-hour inoculation. Groups $(n=6)$ inoculated with Tween $1 \%(\mathrm{C})$, citral (CT), S. aureus (S), and S. aureus treated with citral (S + CT), in an experiment lasting 4 and 8 h. $\vdash$ Significant difference using $p<0.05$, Kruskal-Wallis test.

an indication that the EOC had a positive effect in reducing the microorganism analyzed.

In order to analyze the air pouch model in mice, leukocyte counts of all the animals were done after euthanasia. The group intraperitoneally inoculated with the EOC induced quantitative alterations in leukocytes in peripheral blood. The evaluation of the total count showed significant differences $(p<0.05)$ at $4 \mathrm{~h}$ in the group administered with Tween $1 \%$ (C) or EOC (CT) compared to the infected group (S) or infected and treated group $(\mathrm{S}+\mathrm{CT})$; see Figure 2. However, there were no differences in the total number of leukocytes in the $\mathrm{S}$ to $\mathrm{S}+\mathrm{CT}$ groups in the two days of analysis.

To evaluate the relative quantities of different types of leukocytes in peripheral blood leukocytes, differential counting was performed. Regarding the number of neutrophils, monocytes, and lymphocytes, there were statistically significant differences $(p<0.05)$ in these hematological parameters between the control and treated groups. Differences were observed in the neutrophil groups C and S; C and S + CT; S and CT. Differences were observed for lymphocytes in groups $\mathrm{C}$ and S; C and S + CT in the study time. However, comparing the $\mathrm{S}$ group to the $\mathrm{S}+\mathrm{CT}$ group only in regard to monocytes (Figure 3), significant differences can be seen at $4 \mathrm{~h}$ and $8 \mathrm{~h}$ of infection.

Among endogenous mediators, cytokines play an important role in the host response, and in the dosage of TNF$\alpha$, IL- $1 \beta$, and IL- 6 markers in the lavage, it was possible to assess inflammatory responses in groups. Thus, in Figure 4, we can notice significant differences for the three cytokines, $p<0.05$. However, the group of infected mice compared with 


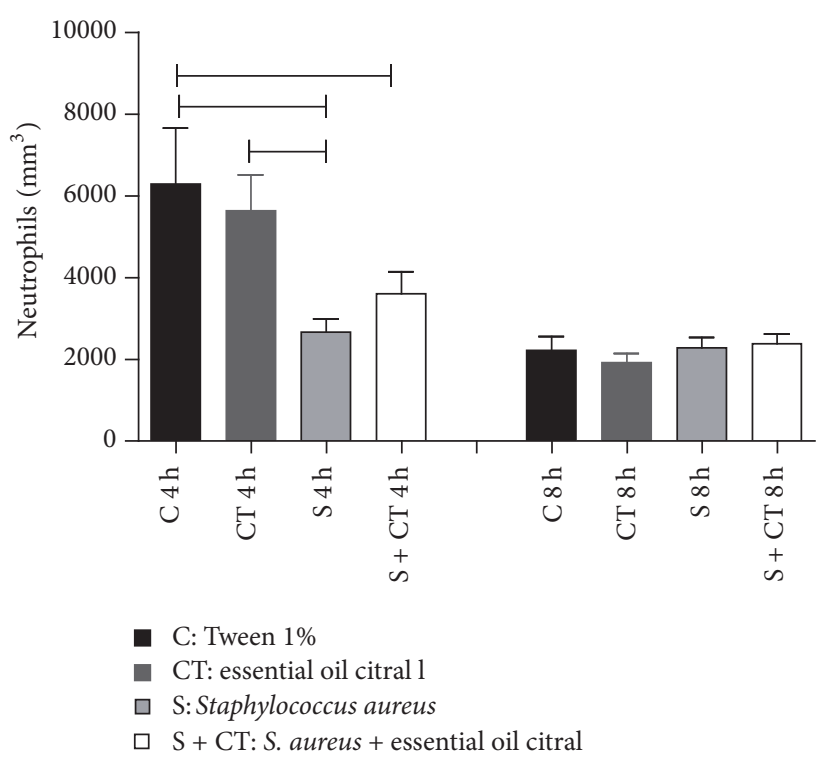

(a)

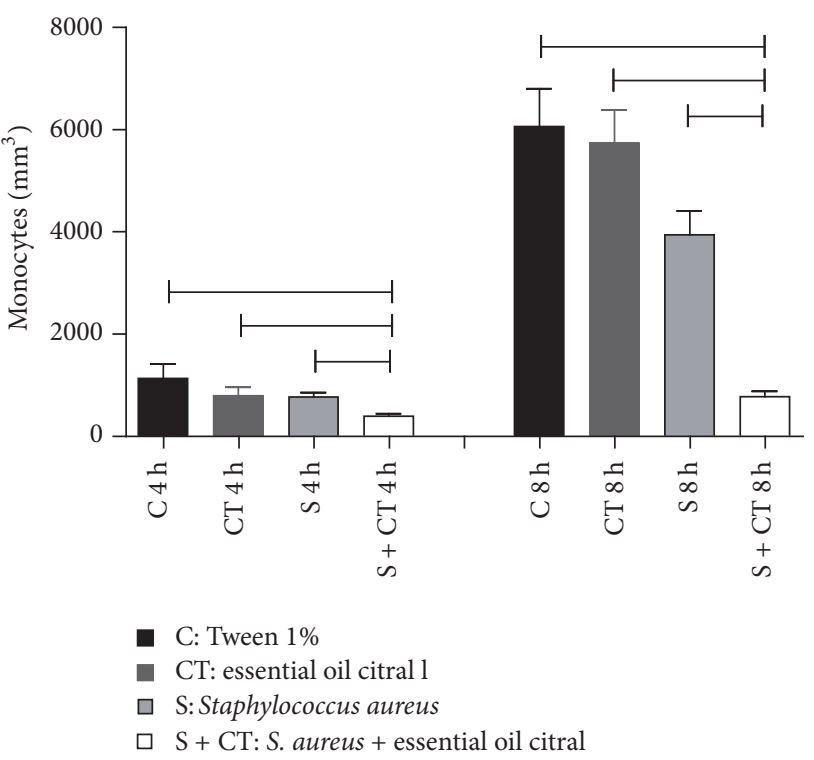

(b)

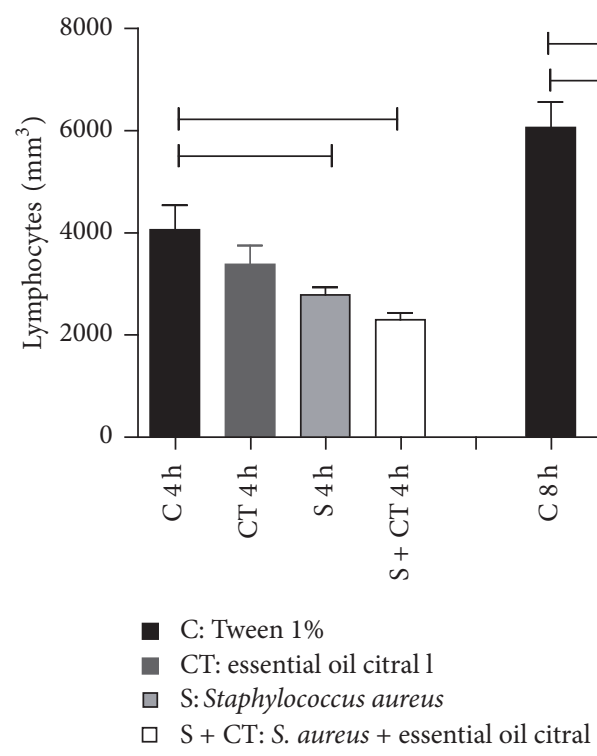

(c)

FIGURE 3: Number of neutrophils (a), monocytes (b), and lymphocytes (c) in the blood of Balb/c mice after 4- and 8-hour inoculation. Groups $(n=6)$ inoculated with Tween $1 \%(\mathrm{C})$, citral (CT), S. aureus (S), and S. aureus treated with citral (S + CT), in an experiment lasting 4 and $8 \mathrm{~h}$. $\mapsto$ Significant difference using $p<0.05$, Kruskal-Wallis test.

the infected and treated group with the EOC in the time of $4 \mathrm{~h}$ showed a significant decrease in IL- 6 and TNF- $\alpha$ levels. IL-1 $\beta$ levels decreased in groups S and S + CT at $4 \mathrm{~h}$; however, the data was not statistically significant.

Analysis of the expression of TNF- $\alpha$, IL- $1 \beta$, and IL- 6 genes showed less variation among the different treatments, where statistical significance was observed between the three genes, $p<0.05$. However, evaluating the inflammatory state induced in the group infected with $S$. aureus against the infected group and treated with EOC, differences can be observed only for the TNF- $\alpha$ gene at $4 \mathrm{~h}, p<0.05$ (Figure 5).

The expression of antibody CD 68 was seen in the brownish color marking of macrophages, being evaluated by immunohistochemistry. There was a response variation between the groups of infected mice compared to the infected and treated group with the EOC, or the group that received the EOC, the time of $4 \mathrm{~h}$, with significant differences, $p<0.05$ (Figure 6).

\section{Discussion}

In infections, an appropriate response is an important aspect that will distinguish whether the host will be cured or not. The use of biologically active natural products has been increasing in recent decades, becoming an alternative for treating various infections. However, scientific evidences on 


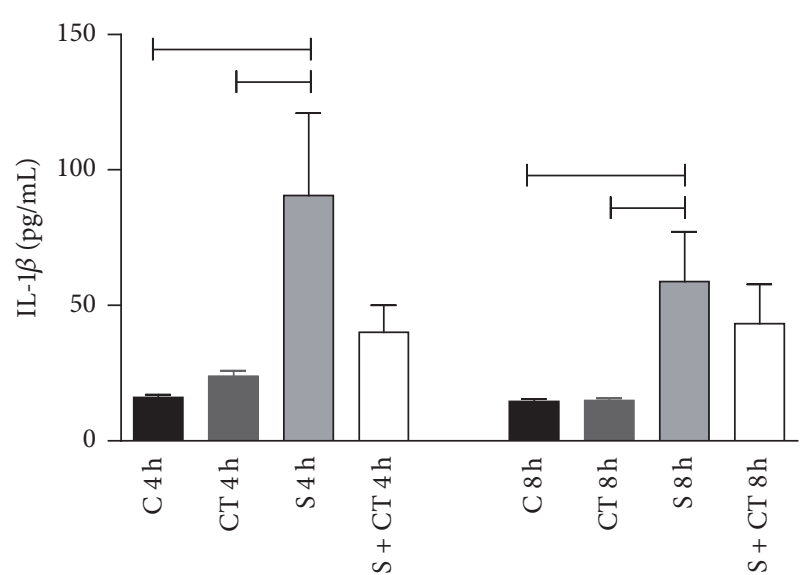

- C: Tween $1 \%$

CT: essential oil citral 1

$\square$ S: Staphylococcus aureus

$\square$ S + CT: S. aureus + essential oil citral

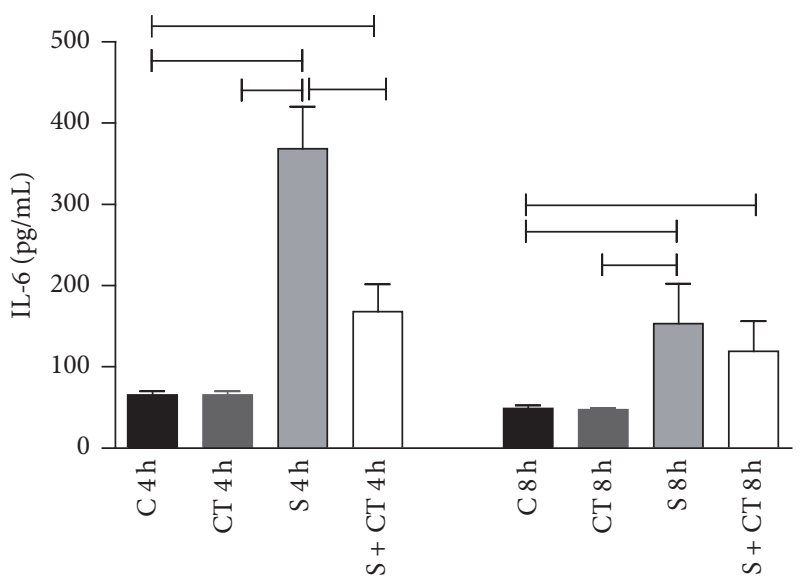

C: Tween $1 \%$

CT: essential oil citral 1

$\square$ S: Staphylococcus aureus

$\square$ S + CT: S. aureus + essential oil citral

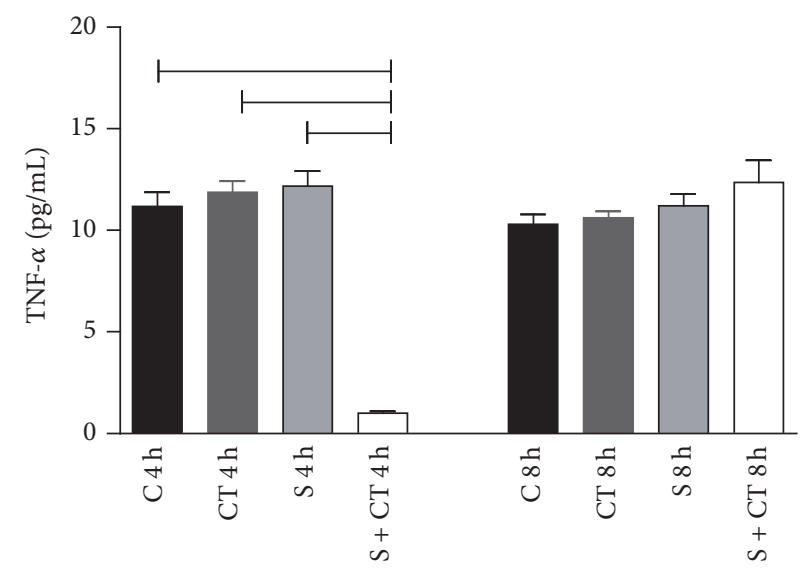

C: Tween $1 \%$

- CT: essential oil citral 1

$\square$ S: Staphylococcus aureus

$\square$ S + CT: S. aureus + essential oil citral

FIGURE 4: Levels of cytokines IL-6, IL-1 $\beta$, and TNF- $\alpha$ in air pouch from Balb/c mice after 4 and 8 hours' inoculation. Groups ( $n=6)$ inoculated with Tween $1 \%(\mathrm{C})$, citral (CT), S. aureus (S) and S. aureus treated with citral (S + CT), in an experiment lasting 4 and $8 \mathrm{~h}$. ${ }^{-}$Significant difference using $p<0.05$, Kruskal-Wallis test.

effectiveness and mechanisms of action for these derivatives are limited, hence, delaying their use in clinical practice [19]. The air pouch tissue is composed of different cell lineages, macrophages, and fibroblasts initially, similar to a synovial cavity, allowing analysis of the inflammatory response, similar to human joint inflammation in rheumatoid arthritis [20].

In the present study, analyzing bacterial load, it was observed that the EOC had a positive effect, since the load of $S$. aureus was reduced in the inflammatory environment when treated on both study days. However, few data report the action of EOC on microorganisms in a model air pouch. Studies assessing ginger oils, lemongrass (has high citral content), mint, pepper, and rosemary against a strain of $S$. aureus have reported bactericidal effects of these oils after $24 \mathrm{~h}$ [21]. It was observed that the EOC does not induce the development of resistance to antibiotics or components of
S. aureus and that subinhibitory concentrations $\left(0.05 \mathrm{mg} \mathrm{mL}^{-1}\right)$ significantly inhibit the formation of biofilm, being considered an important antimicrobial agent [22]. It is believed that the essential oils target different molecular targets for antibiotics, being active against pathogens often resistant to conventional therapy [20]. Other studies report that some essential oils may contain substances that more easily penetrate the lipid layer, as differences in the bacterial cell wall structures allow or prevent entry of substances in bacteria [23].

During inflammatory processes, some mononuclear cells and polymorphonuclear immune system are recruited to the site of infection and can initiate an inflammatory response [24]. Regarding the profile of total leukocytes in peripheral blood, we found no differences between the S and S + CT groups. However, increases were observed in the number of 

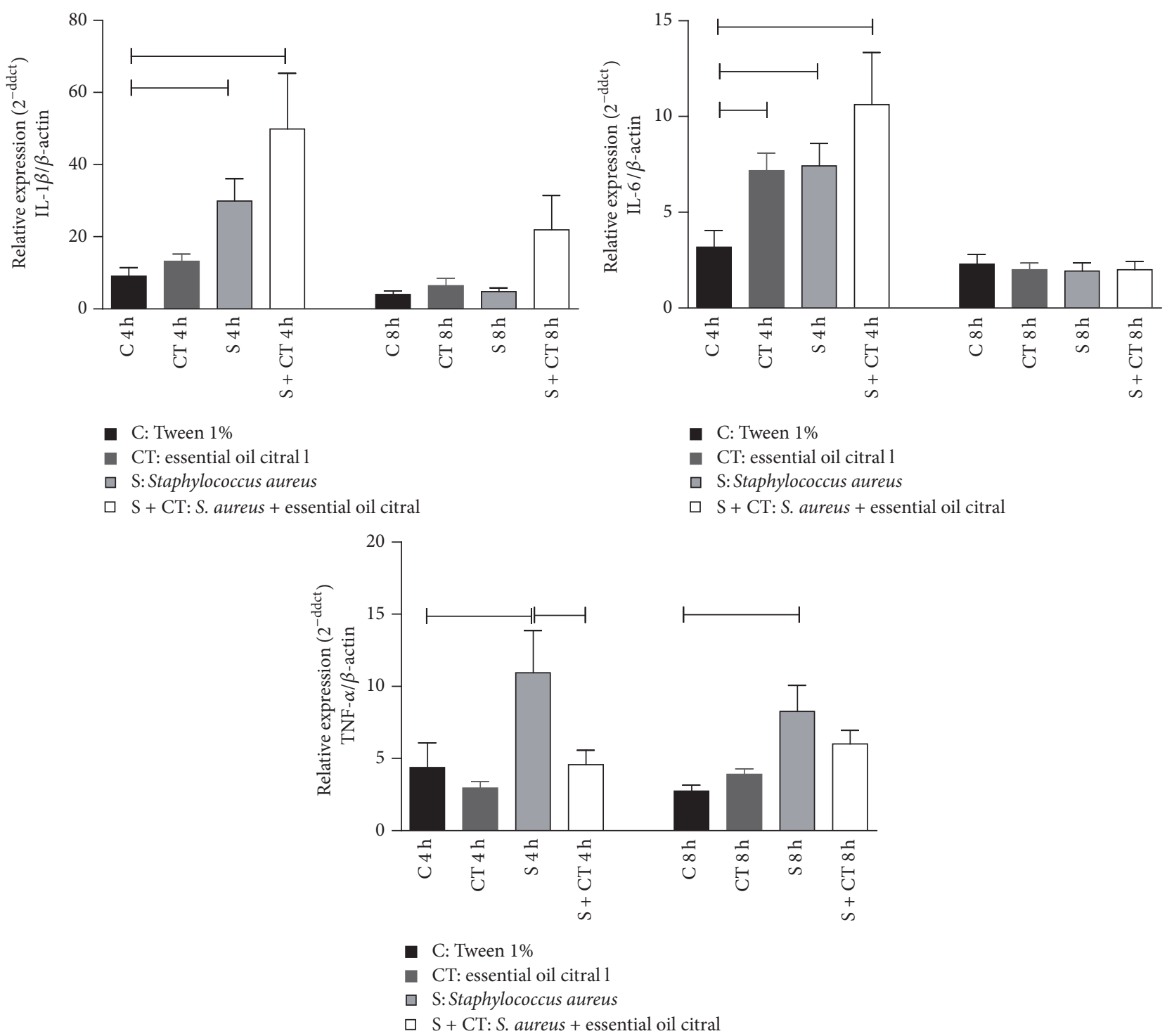

FIGURE 5: Gene expression of IL-1 $\beta$, IL- 6 and TNF- $\alpha$ in air pouch from Balb/c mice after 4 and 8 hours' inoculation. Groups ( $n=6)$ inoculated with Tween $1 \%(\mathrm{C})$, citral (CT), S. aureus (S) and S. aureus treated with citral (S + CT), in an experiment lasting 4 and $8 \mathrm{~h}$. $\mapsto$ Significant difference using $p<0.05$, Kruskal-Wallis test.

cells in C and CT groups. This increase can be influenced by many factors and cannot be solely related to bacterial action, since the air pouch induction causes stress in the animals with consequent release of catecholamines and cortisol, which may lead to an increase in the blood rate of leucocytes [25]. The differential counts of leukocytes (lymphocytes, neutrophils, and monocytes) showed differences in the two times of the experiment. Although there were no differences observed between the groups S and S + CT compared to neutrophils, they are among the major cell types elevated in the bloodstream after a bacterial infection, part of the first line of defense [26]. Different studies with S. aureus demonstrate an increase of neutrophils in the peripheral blood after challenge $[27,28]$, unlike the data found in the two experiments in this study. Two receptors are involved in the assembly of the inflammatory response and migration of neutrophils to the site of inflammation, NOD2 and TLR2 [29]. In the present study, groups C, CT, and S + CT had a higher migration of neutrophils compared to group $\mathrm{S}$. When infection occurs, several chemoattractant factors are released and can be recognized by receptors on the surface of neutrophils, resulting in a strong chemoattractant response that can stimulate and activate a cascade of intracellular signaling, providing neutrophil migration to the inflammatory site [30].

The air pouch model, the local reaction at the infection site, has as its trigger a localized inflammatory response, wherein the release of cytokines can occur so that they eradicate infection [28]. In this study, the analysis of the washed air pouch was observed for all three cytokines studied, showing a reduction in the levels when the animals were treated with EOC. The anti-inflammatory activity of this oil was described [31], demonstrating that it has the property 


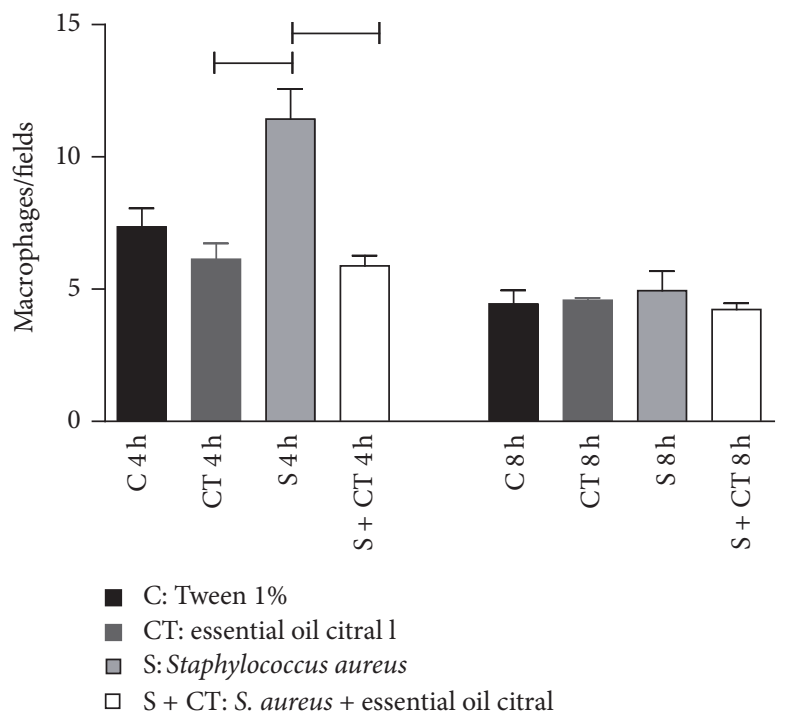

(a)
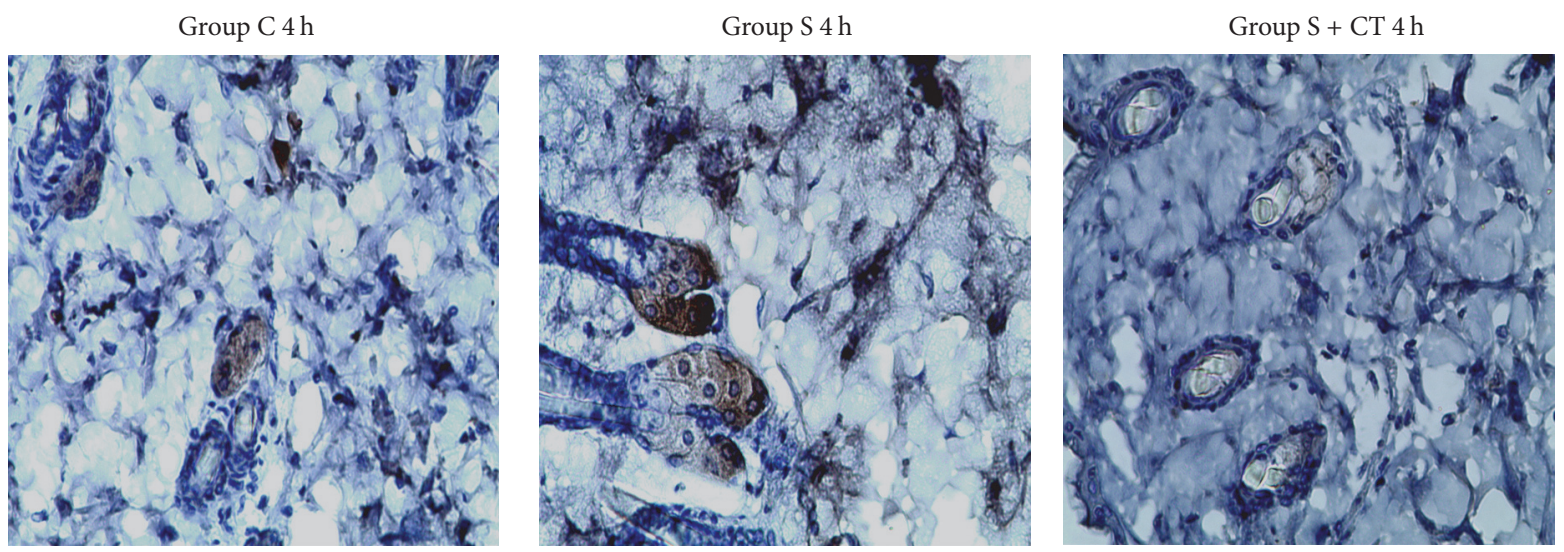

(b)

Figure 6: Immunolocalization of macrophages in air pouch from Balb/c mice after 4- and 8-hour inoculation. (a) Number of macrophages per field. Groups $(n=6)$ : Tween $1 \%(C)$, citral $(\mathrm{CT})$, S. aureus $(\mathrm{S})$, and S. aureus treated with citral $(\mathrm{S}+\mathrm{CT})$. ${ }^{-}$Significant difference with $p<0.05$, Kruskal-Wallis test. (b) Representative photomicrographs of immunolocalization of macrophages. Original magnification $\times 400$.

of inhibiting production of in vivo and in vitro IL- $1 \beta$ and IL6 in mice peritoneal macrophages, as confirmed by findings in this study in relation to IL-6. According to the literature, mice inoculated with carrageenan, the treatment with oral doses of $50-300 \mathrm{mg} / \mathrm{Kg}$ of essential oil obtained from Myrcia ovata plant, rich in EOC, demonstrated a significant effect in reducing pain and inflammation [23]. Regarding the data obtained in the washing with the inflammatory mediators of the air pouch tissue, this result may have occurred due to the mechanism of action, since the pharmacological effect of the most relevant EOC is caused by inhibition of TRPV1, TRPV3, TRPA1, and TRPM8 after activation of these receptors. This inhibition occurs only in initially activated receptors and is irreversible and calcium-independent [32].

Analyzing the expression of TNF- $\alpha$, IL- $1 \beta$, and IL- 6 gene, we can observe significant differences for the three genes. However, evaluating the $S$ and $S+T$ groups, only in the time of $4 \mathrm{~h}$ there were no significant difference levels of TNF- $\alpha$.
Thus, it is believed that the EOC has anti-inflammatory abilities, since it enhances TNF- $\alpha$ as a target for the prevention of inflammatory events induced by chemicals. Although few studies can be found in the literature on the influence of monoterpene compounds in modulating gene expression of TNF- $\alpha$, there are reports that citral oil inhibits an increase in TNF- $\alpha$ levels in RAW 264.7 cells that are stimulated with lipopolysaccharide (LPS) [33]. In the same way, it was observed in the literature that the EOC at concentrations of 50 and $100 \mu \mathrm{g} / \mathrm{mL}$ reduced the TNF- $\alpha$ relative expression compared to treatment with LPS [34]. Authors analyzing alveolar macrophages observed that treatment with citral oil in mice with lung injury induced by LPS inhibited TNF- $\alpha$, IL-1 $\beta$, and IL-6 levels both in vivo and in vitro, demonstrating that the EOC can inhibit a possible inflammatory response [18]. It was also demonstrated that the alcoholic extract of lemongrass, which has as major compound citral, reduced the generation of TNF- $\alpha$ in bronchoalveolar macrophages stimulated with 
LPS, enhancing the anti-inflammatory potential of citral and indicating that modulation of the COX- 2 and TNF- $\alpha$ genes can be one of the mechanisms involved in such activity [35].

The dosage of inflammatory markers by ELISA compared to gene expression showed differences in results, particularly IL- 6 and IL- $1 \beta$. This could happen through a change in the amount of cytokines, due to the expression or not of a gene regulated by a site-specific methylation. The immunological response may be compromised by epigenetic mechanisms, including gene silencing by methylation in the promoter region and blocking gene transcription [36]. In addition, the EOC may cause possible interference in the expression of these genes. In the line RAW 264.7 mice macrophages stimulated with LPS, citral inhibited the phosphorylation interaction with inhibitory proteins $\mathrm{kB}(\mathrm{IkB})$, blocking translocation of the p50 and p65 subunits of NF-kB and leading to a low expression of inducing enzyme nitric oxide synthetase (iNOS) [37].

This study also demonstrated a relationship between the production of cytokines and bacterial load, since the lower bacterial load in animals treated seems to be related to lower IL- 6 , IL- $1 \beta$, and TNF- $\alpha$ expression in washed air pouch and TNF- $\alpha$ of gene expression. Regarding the effectiveness in times of treatment chosen, it seems that with $4 \mathrm{~h}$ the EOC had better action; however, little is known about the performance of this oil in animals, and more studies need to be conducted. A study on the stability of the major constituents of the essential oil of lemongrass, rich mainly in citral and myrcene, reported a significant variation in the degradation of these compounds in relation to temperature and time; however, the interaction between the variants was not significant for citral [38].

Thus, our results showed that the use of the essential oil citral in the local therapy of infectious diseases triggered by $S$. aureus showed positive action. However, the existence of a harmful action or interference in the physiology and/or structures of bacterial cells of this natural product and its bioavailability when used in living beings are not well understood. Given the above information and grounded in the literature, this was the first study to assess the joint influence of the air pouch model, essential oil citral, and $S$. aureus, since the EOC appears to be a potential therapeutic agent for treating local infections triggered by $S$. aureus. In conclusion, the treatment with essential oil citral in the infection triggered by $S$. aureus led to a reduction of some features of acute inflammation, including the number of monocytes. The TNF- $\alpha$ cytokine has proved to be a more sensitive biomarker, in ELISA and RT-qPCR array. By reducing TNF- $\alpha$ concentration, EOC promoted the reduction of transcription of genes related to proinflammatory cytokines. The action of the EOC seems to have a better response in a period of $4 \mathrm{~h}$; thus, this suggests that the EOC can act as a modulator of the immune system by decreasing cellular migration and the production of proinflammatory cytokines following infection with S. aureus.

\section{Competing Interests}

The authors declare that there are no competing interests regarding the publication of this paper.

\section{Acknowledgments}

This study was supported by Fundação de Amparo a Pesquisa do Estado da Bahia (RED0016/2014). The authors thank AcademicEnglishSolutions.com for revising the English.

\section{References}

[1] S. H. M. Rooijakkers, K. P. M. van Kessel, and J. A. G. van Strijp, "Staphylococcal innate immune evasion," Trends in Microbiology, vol. 13, no. 12, pp. 596-601, 2005.

[2] H. K. Kim, V. Thammavongsa, O. Schneewind, and D. Missiakas, "Recurrent infections and immune evasion strategies of Staphylococcus aureus," Current Opinion in Microbiology, vol. 15, no. 1, pp. 92-99, 2012.

[3] H. F. L. Wertheim, D. C. Melles, M. C. Vos et al., "The role of nasal carriage in Staphylococcus aureus infections," Lancet Infectious Diseases, vol. 5, no. 12, pp. 751-762, 2005.

[4] A. M. Bernard and G. R. Bernard, "The immune response: targets for the treatment of severe sepsis," International Journal of Inflammation, vol. 2012, Article ID 697592, 9 pages, 2012.

[5] M. R. N. Celes, C. M. Prado, and M. A. Rossi, "Sepsis: going to the heart of the matter," Pathobiology, vol. 80, no. 2, pp. 70-86, 2012.

[6] L. Ding, H. Jing, B. Qin et al., "Regulation of cell division and growth in roots of Lactuca sativa L. Seedlings by the ent-kaurene diterpenoid rabdosin B," Journal of Chemical Ecology, vol. 36, no. 5, pp. 553-563, 2010.

[7] F. Bakkali, S. Averbeck, D. Averbeck, and M. Idaomar, "Biological effects of essential oils-a review," Food and Chemical Toxicology, vol. 46, no. 2, pp. 446-475, 2008.

[8] G. Singh, S. Maurya, M. P. deLampasona, and C. A. N. Catalan, "A comparison of chemical, antioxidant and antimicrobial studies of cinnamon leaf and bark volatile oils, oleoresins and their constituents," Food and Chemical Toxicology, vol. 45, no. 9, pp. 1650-1661, 2007.

[9] N. Dudai, Y. Weinstein, M. Krup, T. Rabinski, and R. Ofir, "Citral is a new inducer of caspase- 3 in tumor cell lines," Planta Medica, vol. 71, no. 5, pp. 484-488, 2005.

[10] R. Irkin and M. Korukluoglu, "Effectiveness of cymbopogon citratus l. essential oil to inhibit the growth of some filamentous fungi and yeasts," Journal of Medicinal Food, vol. 12, no. 1, pp. 193-197, 2009.

[11] A. K. Tyagi and A. Malik, "Liquid and vapour-phase antifungal activities of selected essential oils against candida albicans: microscopic observations and chemical characterization of cymbopogon citratus," BMC Complementary and Alternative Medicine, vol. 10, article 65, 2010.

[12] K. B. Laupland, T. Ross, and D. B. Gregson, "Staphylococcus aureus bloodstream infections: risk factors, outcomes, and the influence of methicillin resistance in Calgary, Canada, 20002006," Journal of Infectious Diseases, vol. 198, no. 3, pp. 336-343, 2008.

[13] G. Sakoulas and R. C. Moellering Jr., "Increasing antibiotic resistance among methicillin-resistant Staphylococcus aureus strains," Clinical Infectious Diseases, vol. 46, supplement 5, pp. S360-S367, 2008.

[14] A. Tegnell, K. Grabowska, A. Jacobsson, M. Andersson, J. Giesecke, and L. Öhman, "Study of developed resistance due to antibiotic treatment of coagulase-negative Staphylococci," Microbial Drug Resistance, vol. 9, no. 1, pp. 1-6, 2003. 
[15] C. K. Naber, "Future strategies for treating Staphylococcus aureus bloodstream infections," Clinical Microbiology and Infection, vol. 14, no. 2, pp. 26-34, 2008.

[16] M. N. Boukhatem, M. A. Ferhat, A. Kameli, F. Saidi, and H. T. Kebir, "Lemon grass (cymbopogon citratus) essential oil as a potent anti-inflammatory and antifungal drugs," Libyan Journal of Medicine, vol. 9, 2014.

[17] M. I. Ortiz, M. P. González-García, H. A. Ponce-Monter, G. Castañeda-Hernández, and P. Aguilar-Robles, "Synergistic effect of the interaction between naproxen and citral on inflammation in rats," Phytomedicine, vol. 18, no. 1, pp. 74-79, 2010.

[18] Y. Shen, Z. Sun, and X. Guo, "Citral inhibits lipopolysaccharideinduced acute lung injury by activating PPAR- $\gamma$," European Journal of Pharmacology, vol. 747, pp. 45-51, 2015.

[19] S. Kar Mahapatra, S. Bhattacharjee, S. P. Chakraborty, S. Majumdar, and S. Roy, "Alteration of immune functions and Th1/Th2 cytokine balance in nicotine-induced murine macrophages: immunomodulatory role of eugenol and $\mathrm{N}$-acetylcysteine," International Immunopharmacology, vol. 11, no. 4, pp. 485-495, 2011.

[20] D. B. Duarte, M. R. Vasko, and J. C. Fehrenbacher, "Models of inflammation: carrageenan air pouch," in Current Protocols in Pharmacology, chapter 5, unit 5.6, 2012.

[21] L. N. Barbosa, I. S. Probst, B. F. M. T. Andrade et al., "In vitro antibacterial and chemical properties of essential oils including native plants from Brazil against pathogenic and resistant bacteria," Journal of Oleo Science, vol. 64, no. 3, pp. 289-298, 2015.

[22] J. Apolónio, M. L. Faleiro, M. G. Miguel, and L. Neto, "No induction of antimicrobial resistance in Staphylococcus aureus and Listeria monocytogenes during continuous exposure to eugenol and citral," FEMS Microbiology Letters, vol. 354, no. 2, pp. 92101, 2014.

[23] G. C. A. M. Dos Santos, G. A. M. Gomes, G. M. A. Gonçalves et al., "Essential oil from Myrcia ovata: chemical composition, antinociceptive and anti-inflammatory properties in mice," Planta medica, vol. 80, no. 17, pp. 1588-1596, 2014.

[24] J. K. Kundu and Y.-J. Surh, "Inflammation: gearing the journey to cancer," Mutation Research-Reviews in Mutation Research, vol. 659, no. 1-2, pp. 15-30, 2008.

[25] R. J. Benschop, M. Rodriguez-Feuerhahn, and M. Schedlowski, "Catecholamine-induced leukocytosis: early observations, current research, and future directions," Brain, Behavior, and Immunity, vol. 10, no. 2, pp. 77-91, 1996.

[26] J. S. Cho, Y. Guo, R. I. Ramos et al., "Neutrophil-derived IL$1 \beta$ is sufficient for abscess formation in immunity against Staphylococcus aureus in mice," PLoS Pathogens, vol. 8, no. 11, Article ID e1003047, 2012.

[27] R. A. Proctor, "Is there a future for a Staphylococcus aureus vaccine?” Vaccine, vol. 30, no. 19, pp. 2921-2927, 2012.

[28] K. M. Rigby and F. R. DeLeo, "Neutrophils in innate host defense against Staphylococcus aureus infections," Seminars in Immunopathology, vol. 34, no. 2, pp. 237-259, 2012.

[29] H. Wang, G. Yu, H. Yu et al., "Characterization of TLR2, NOD2, and related cytokines in mammary glands infected by Staphylococcus aureus in a rat model," Acta Veterinaria Scandinavica, vol. 57, no. 1, article 25, 2015.

[30] T. J. Foster, "Immune evasion by staphylococci," Nature Reviews Microbiology, vol. 3, no. 12, pp. 948-958, 2005.

[31] T. F. Bachiega and J. M. Sforcin, "Lemongrass and citral effect on cytokines production by murine macrophages," Journal of Ethnopharmacology, vol. 137, no. 1, pp. 909-913, 2011.
[32] S. C. Stotz, J. Vriens, D. Martyn, J. Clardy, and D. E. Clapham, "Citral sensing by Transient [corrected] receptor potential channels in dorsal root ganglion neurons," PLOS ONE, vol. 3, no. 5, p. e2082, 2082.

[33] C.-T. Lin, C.-J. Chen, T.-Y. Lin, J. C. Tung, and S.-Y. Wang, "Antiinflammation activity of fruit essential oil from Cinnamomum insularimontanum Hayata," Bioresource Technology, vol. 99, no. 18, pp. 8783-8787, 2008.

[34] M. de Paula Porto, G. N. da Silva, B. C. O. Luperini et al., "Citral and eugenol modulate DNA damage and pro-inflammatory mediator genes in murine peritoneal macrophages," Molecular Biology Reports, vol. 41, no. 11, pp. 7043-7051, 2014.

[35] M. Tiwari, U. N. Dwivedi, and P. Kakkar, "Suppression of oxidative stress and pro-inflammatory mediators by Cymbopogon citratus D. Stapf extract in lipopolysaccharide stimulated murine alveolar macrophages," Food and Chemical Toxicology, vol. 48, no. 10, pp. 2913-2919, 2010.

[36] S. B. Baylin, "DNA methylation and gene silencing in cancer," Nature Clinical Practice Oncology, vol. 2, supplement 1, pp. S4S11, 2005.

[37] H. J. Lee, H. S. Jeong, D. J. Kim, Y. H. Noh, D. Y. Yuk, and J. T. Hong, "Inhibitory effect of citral on NO production by suppression of iNOS expression and NF- $\kappa$ B activation in RAW264.7 cells," Archives of Pharmacal Research, vol. 31, no. 3, pp. 342-349, 2008.

[38] G. F. Santoro, M. G. Cardoso, L. G. L. Guimarães, J. M. Freire, and M. J. Soares, "Anti-proliferative effect of the essential oil of Cymbopogon citratus (DC) Stapf (lemongrass) on intracellular amastigotes, bloodstream trypomastigotes and culture epimastigotes of Trypanosoma cruzi (Protozoa: Kinetoplastida)," Parasitology, vol. 134, no. 11, pp. 1649-1656, 2007. 


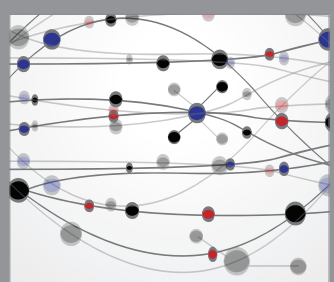

The Scientific World Journal
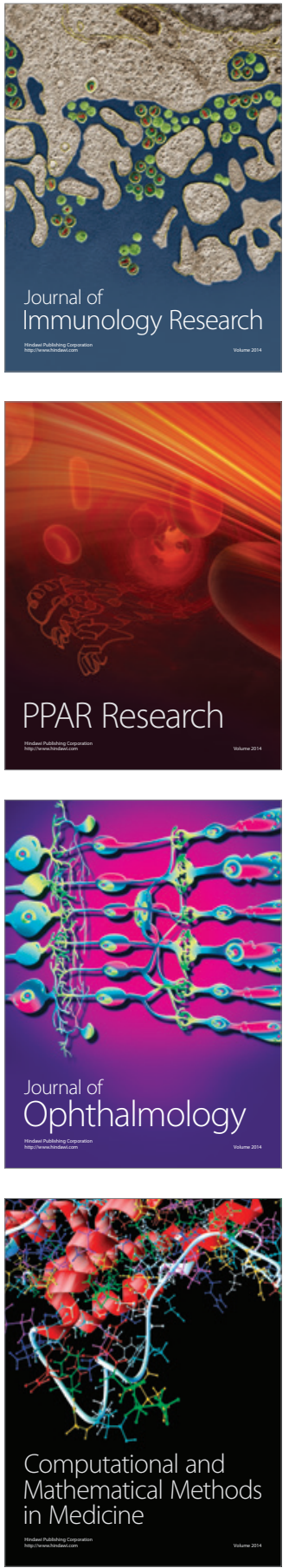

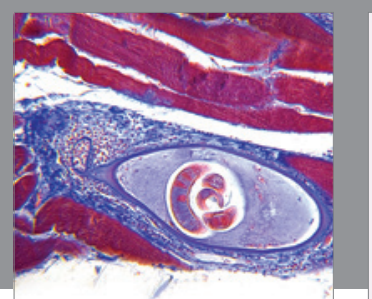

Gastroenterology Research and Practice
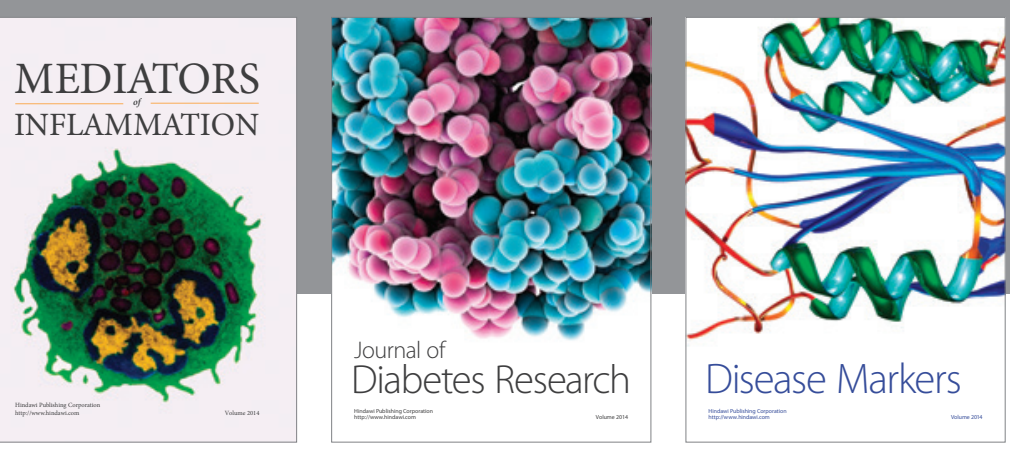

Disease Markers

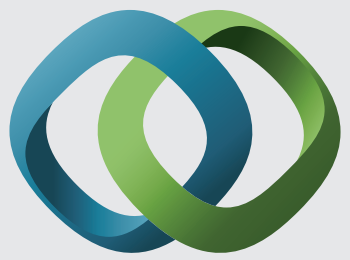

\section{Hindawi}

Submit your manuscripts at

https://www.hindawi.com
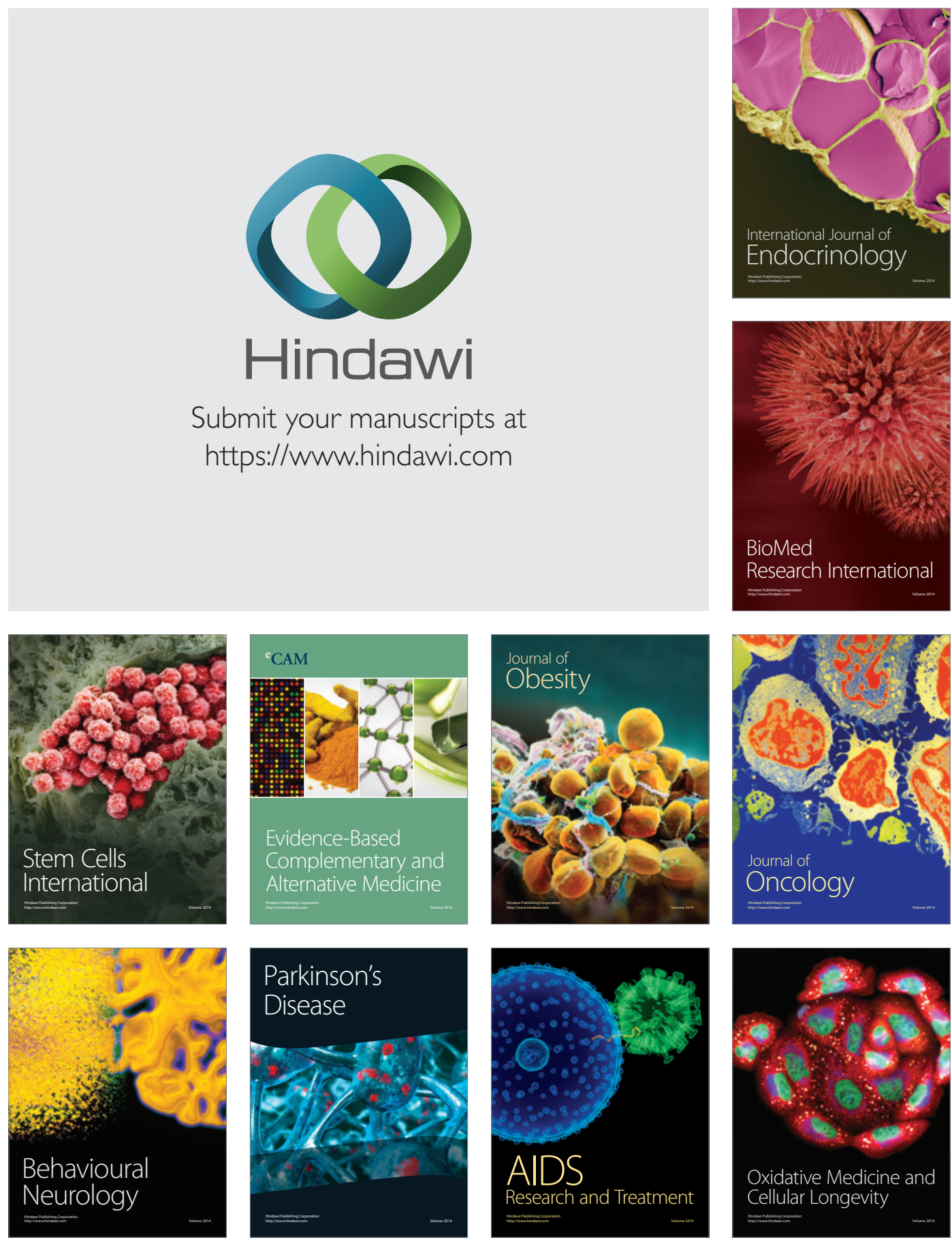